\title{
Roots and Causes of Occupational Stress amongst Female Academics in Universities of Technology in South Africa
}

\author{
Ms Mercillene Mathews ${ }^{1}$, Dr Njabulo Khumalo ${ }^{1} \&$ Prof Bongani Innocent Dlamini $^{1}$ \\ ${ }^{1}$ Durban University of Technology, South Africa \\ Correspondence: Njabulo Khumalo, Durban University of Technology, South Africa.
}

Received: December 7, 2021

Accepted: January 27, 2022

Online Published: January 28, 2022

doi:10.5430/ijhe.v11n7p37

URL: https://doi.org/10.5430/ijhe.v11n7p37

\begin{abstract}
Stress and stress-related problems have negative human resource and financial implications for Universities of Technology (UoT) in terms of absenteeism, productivity, organizational effectiveness, employee morale and medical aid subsidies. For tertiary institutions, the impact of stressed academics on core business activities relating to students and examinations are far-reaching. The paper assessed the roots and causes of occupational stress amongst female academics in a UoT in South Africa. The paper adopted a qualitative research approach with a focus group of selected female academics in the UoT. The paper revealed that workload and performance management, as well as family life and personal life; teaching vs research and administration; Covid-19 and online teaching and learning; holidays and leave and lack of leave; meetings and support deficiency; resources and lack of care and empathy, as well as poor HR, bullying and imposition and a lack of professionalism; nepotism and favouritism; retrenchments and instability, along with poor recognition and appreciation, were the roots that contribute to occupational stress in the UoT in SA. The paper recommends that effective interventions be implemented by the UoT in order to manage the stress of these female academics, thereby reducing the negative impact thereof on themselves and the institution. University policy-makers should devise a variety of solutions in a well-balanced package that places responsibility on both the university and staff to manage occupational stress.
\end{abstract}

Keywords: stress, occupational stress, stressor, University of Technology, focus group

\section{Introduction}

A number of factors contribute to university employees' morale, which need to be addressed as a matter of urgency before talented academics leave their current universities and find better employment elsewhere. University leaders should not procrastinate on addressing these factors as they have a significant impact (Khumalo, 2022). Stress has been shown to have a negative influence on employee productivity and job satisfaction in a variety of occupations. It is also thought to be a significant contributory factor to absenteeism and low staff morale, as well as having severe consequences for sustainability and organizational development. As a result, many organizations have recognized the significance of addressing the issue of workplace stress (Leung, Liang and Olomolaiye, 2014). Academic staff at higher education institutions bear a tremendous degree of responsibility, not only to their administration, but also to their students' parents and sponsors, who are constantly demanding good performance ratings for their children, which can be a source of stress for academics.

The Higher Education Commissions' (HEC) responsibility, according to Raza (2012), is to increase the progress of institutes that direct the country toward appropriate sustainability. Moreover, Universities of Technology (UoTs) are largely responsible for supporting research and development, as well as increasing instructional capacity. These elements have an impact on university performance, putting academics under much stress. Additionally, other variables such as strained peer relationships, insufficient working infrastructure and poor economic conditions can all contribute to stress. Stress should not be dismissed as a trivial issue since stressed academics will be unable to achieve the criteria of higher educational institutions, thereby lowering the country's educational quality. In this context, this paper assesses the root causes of stress amongst female academics from the perspective of a UoT in South Africa, since occupational stress is one of the most frequent work-related health concerns in the world, and is becoming a major concern in a variety of industries, including the post-compulsory education sector. 


\section{Literature Review}

\subsection{Occupational Stress}

Occupational stress refers to the unpleasant physiological and psychological effects that individuals experience as a result of their inability to cope with the obligations placed on them (Miller, 2014). When workplace stress levels rise, employee turnover rates rise as well. As a result, occupational stress contributes to a variety of issues and hindrances in businesses, namely absenteeism, inefficiency and inadequate health resources (Miller, 2014). Occupational stress can be caused by too much or too little work, time pressure, deadlines and physical strain in the workplace. Negative employment environments also cause social and psychological stress (Wadesango, Gudyanga \& Mberewere, 2015:31-35).

\subsection{Factors That Lead to Occupational Stress}

Attempts to pinpoint the causes of occupational stress have turned up a slew of suspects. According to Breakwell (2015), Cary Cooper (Cooper, 1983) produced a concise yet comprehensive list of six sources of work stress, namely: Workplace Conditions - i.e. quantitative and qualitative job overload, people decisions, physical risk and technological stress; Role Stress - Role ambiguity, gender prejudice and gender-role stereotypes are all examples of role stress; Interpersonal Factors - Inadequate work and social support systems, a lack of management concern for employees, political rivalry, jealously or wrath are all examples of interpersonal factors; Professional Development Under-promotion, over-promotion, job security and unfulfilled ambitions; Organizational Structure - rigid and impersonal structures, political struggles, insufficient supervision or training, as well as a lack of participation in decision-making; and Home-work interface - Spillover, lack of support from spouse, marital conflict and dual career stress.

In educational contexts, public health crises like COVID-19 can inspire creativity and stimulate out-of-the-box thinking (Singh, Steele and Singh 2021). Instructors and academic administrators must focus on developing proper infrastructure to support hybrid and blended learning approaches in order to give relevant and engaging learning experiences to students. Focusing on faculty capacity building is critical in order for them to become more familiar with online learning methodologies, e-Learning tools, and the use of new technology to assist teaching and learning. It is also necessary to have a high level of emergency readiness so that instructors, administrators, and students can quickly react to developments that are beyond their control. This readiness will necessitate the deployment of resources to address mental health issues as well as further training in pedagogical methods (Singh, Steele and Singh 2021).

\subsection{Work Environment Factors}

Insecurity and a lack of job advancement are two more sources of workplace stress. Davis (2012) states that employees who believe that they are being promoted too slowly, who are insecure about their career prospects, or who believe that their objectives are being hindered are more likely to be stressed. External control from superiors, according to Prabu (2015:63), is another source of workplace stress. Since he or she is the only one who makes decisions, the Head of Department, for example, may cause stress for a member of his or her department. Occupational stress is also caused by a top-down approach within an organization. Employees may believe that their rights are being violated since they are not involved in decision-making, despite the fact that they are the ones who labour. Employees are additionally stressed by delayed remuneration or paychecks, since they would be unable to meet their needs as bread-winners. Bickford (2005) describes Autonomy as a term that refers to both participation and control. When a worker lacks control over his or her assigned responsibilities, or has no say in the decision-making process that influences how these tasks are completed, this frequently results in workplace stress (Bickford, 2005), which Nambei and Mefi also highlight (2020:8). Lack of control is the most stressful factor in the workplace.

Nambei and Mefi (2020:8) mention that when employees believe that they have little control over their participation or the outcome of their work, they become extremely agitated. Another kind of work stress is the 'treadmill syndrome' (Hudson-Allez, 1999), which occurs when employees have too much or too little to perform on a regular basis. Workplace stress can also be caused by having too much or too little work to do because it puts pressure on an employee. Bickford (2005) posits that when a worker's talents, expertise and capacities are out-matched or exceeded by the volume of labor, stress results. Some employees are overworked as a result of having too many duties. Others work around the clock, not necessarily at the same time every day, but at various times throughout the day, as well as at home. Employees with too much to do and too many duties fall into this category. These employees are unable to complete their tasks due to unplanned interruptions, putting them behind schedule. 


\subsection{Theoretical Framework}

The study will adopt the Transactional Model of Stress and Coping for the theoretical framework (Lazarus and Folkman, 1984). The model argues that one's experience of stress is ultimately a system of appraisal, response and adaptation. It is the most widely used theoretical framework for stress and coping (Frydenberg and Lewis in Devonport et al. 2008:71). The proposition of the Transactional Model is that coping with stress is a result of one's situational appraisals and emotional responses or cognitive appraisal of stressors. According to the model, a primary appraisal of the impact of a stressor on well-being will give rise to a secondary appraisal in which the person will assess the potential harm and how to mitigate it, or the potential gains from the stressor and how to maximise those. Hence, a cognitive underpinning for coping with stressors is created. However, coping would only be necessary should the appraisal indicate a stressful, negative or malignant stressor. If the appraisal is positive and the stressor is appraised as benign, coping responses will not be required. Tertiary appraisal or re-appraisal occurs when a coping response is reviewed, upon which another coping response may follow. The Transactional Model of Lazarus and Folkman (1984) postulates that coping was seen as mainly a reactive response to stress, whereby the strategy is used after the stress is experienced. However, the model has been adapted by various authors like Greenglass (2002) and Schwarzer and Renner (2002), who posit that coping is something that is exhibited before stress occurs, that is, a proactive strategy.

\subsection{Causes of Occupational Stress}

Work is an essential component of human existence. A satisfying and fulfilling job is a sufficient and beneficial element of people's lives, allowing them to feel satisfied and meaningful at work. However, when a job does not allow an individual to perform to their full potential, tension will occur. Moreover, when individuals are faced with work expectations and pressures that are not suited to their abilities and knowledge, they may experience occupational stress. Workplace stress can occur in a variety of situations, but it is frequently regarded as being exacerbated when employees receive little or no support from their bosses and co-workers (WHO, 2017). Workplace pressure is unavoidable and might be considered a natural part of life. However, stress that exceeds a certain threshold can cause psychological and physiological problems, which can have a detrimental impact on an employee's performance in the workplace (Harmsen, Helms-Lorenz, Maulana \& van Veen, 2018:626). Working in the tertiary education sector is a demanding career with many responsibilities. Work overload, job demands, job control, tight timetables, remuneration imbalances, position ambiguity and conflict are all common stressors that academics face (Leung, Liang \& Olomolaiye, 2014). As Leung et al. (2014) point out, the majority of academics have experienced stress, anxiety or depression as a result of their jobs. Job stress can come from a variety of sources, as listed below:

\subsubsection{Individual Stressors}

Many different types of stressors can be generated on an individual level in the context of personal or organizational life. Individual stressors are greatly influenced by a person's personality qualities and change restrictions. Individual stressors include the following: Role stress can develop as a result of role conflict or ambiguity and Role conflict happens when two or more roles are incompatible (work and family). In some cases, an individual's many responsibilities may have conflicting demands, causing stress as a result of issues in meeting the conflicting role needs (Hitt, Miller \& Colella, 2018). Changes in one's life and career: Changes in one's life and career cause stress. Stress is more prevalent in higher education categories, according to research. Personality traits can be a cause of stress, with persons with a strong work ethic at risk of burnout. These people have a pattern of activity that includes frequent movement, multi-tasking and experiencing time pressure, all of which contribute to a higher level of stress.

\subsubsection{Group Stressors}

The group can also be a cause of stress, with the following key group stressors: Lack of group cohesion: group cohesiveness is critical for an individual's interaction in a group. When people are denied this sense of belonging, it can be stressful. Lack of social support: People who obtain social support from other members of their group are able to meet their social needs. They feel better about themselves when they can talk about their troubles and joys with others. However, for people who do not have this social support, it might be stressful. Conflicts that emerge in group interactions can cause much stress for the members of the group (Champoux, 2010).

\subsubsection{Organisational Stressors}

Devonport et al. (2008:71) describe organisational stress as an outcome of the interplay between an individual's personal characteristics, the environment, the demands placed upon them and their ability to cope. Organisational stress, or any type of stress for that matter, does not always imply deleterious consequences. Optimal levels of stress 
can have functional/positive rather than dysfunctional/negative outcomes as employees work more effectively and may experience greater satisfaction. Such an occurrence is referred to as eustress. However, when stress levels surpass these optimal levels, people become distressed and dysfunctional outcomes like reduced performance result. Studies by a number of researchers like Lazarus and Folkman (1999), Costa and McRae (1992), etc. reveal that mitigating or moderating factors exist, which reduce or eliminate the negative effects of organisational stress. Since an organization is made up of both groups and people, individual and collective stressors can occur in the workplace. The following are the key organizational stressors: Policies of the organization - whereas ambiguous or unfavourable policies may cause tension amongst employees, organizational policies provide instructions for action. Unrealistic work descriptions, rigid standards and unequal incentives are just a few examples of stressors. Organizational structure- An organization's organizational structure establishes formal relationships amongst its members. Due to insufficient relationships between individuals and groups, any flaws in an organization's structure act as pressure. Lack of promotion opportunities, participation in decision-making and line and staff friction are all sources of stress. Organizational processes- Inadequate organizational processes, such as poor communication or an insufficient flow of information, induces stress amongst employees. Physical conditions- Work performance is influenced by physical conditions. Individuals are stressed by poor physical conditions such as excessive noise, a lack of privacy or an indoor temperature that is either excessively hot or cold (Champoux, 2010). Huczynski and Buchanan (2013) in Kruger et al. (2015:96) expound on the following six stressors in the organization:

- Unpleasant work environment: stress amongst workers may be triggered by conditions such as noise pollution, poor ventilation, unsafe or unhealthy work conditions, to name a few;

- Inappropriate job design: workload in terms of work overload or underload, a lack of training and no participation in decision-making are examples of stressors that fall into this category of organizational stressors;

- Management/leadership style: poor management style, autocratic leadership, inconsistent decision-making and a lack of trust are examples of stressors in this category;

- Poor work relations: poor interpersonal relationships with colleagues or supervisors, workplace harassment or bullying are stressors in this category;

- Uncertainty about the future: issues like job insecurity and ambiguity about one's future in the organization are stressful factors; and

- Type of career: some professions, by their very nature, are stressful. For example, emergency workers, protection services personnel and teachers are more prone to stress.

\subsection{Occupational Stress amongst Female Academics}

Role conflict and ambiguity in female employees, according to Dhar and Magotra (2018), are two characteristics that can contribute to increased stress levels in women. The authors claim that when people have many roles, it might cause them much stress. "A female employee's job as a manager, for example, may compel her to work on Saturdays, while her job as a mother demands her to attend her daughter's soccer game on the same day" (Aamodt 2004:478).

\subsubsection{Effects of Stress on Academics}

Kinman (2016) discovered that academics who reported higher levels of stress were less content with their jobs, had higher absenteeism and were more likely to leave teaching. She also discovered that lower levels of stress are linked to improved teaching technique efficacy. According to Fisher (1994) cited by Tight (2012), educators are stressed by the new outcomes-based education method; the high crime rate in the country; having to deal with current political change; and corruption in state departments.

\subsubsection{Low Teacher Morale}

"The degenerating manner of teachers is a sign of the stressful conditions of work and the disappointment they suffer because of unmet expectations," (Gold and Roth 2013). Several studies have labeled this low morale as "Education in Crisis" or "A Profession in Crisis". Female academics' morale is low, according to empirical research, because the benefits they receive are insufficient to meet their needs, and outcomes-based education has caused teachers to be uncertain.

\subsubsection{Job Dissatisfaction}

"Research evidence supports the concept that sources of stress in a particular work, coupled with individual characteristics, might be predictive of stress symptoms, which may manifest themselves in the form of job 
dissatisfaction," (Travers and Cooper 2012). One of the most common behavioral manifestations of stress in the workplace is job discontent. Kyriacou (2001) cited by Collie and Shapka (2012:1189) conducted a study that revealed a significant level of unhappiness with teaching as a profession. Female academics mentioned compensation, career structure, advancement chances and occupational standing as some of the factors that contributed to their dissatisfaction. "Teacher discontent appears to be a key reason in teachers leaving the profession in many countries", according to Kryiacou (2011:161). The author also believes that teacher satisfaction is linked to how they feel about their teaching jobs, or their motivation levels. According to Kryiacou (2011:165), "more administrative support and leadership, good student behavior, a great school culture and teacher autonomy" are some of the factors that contribute to teacher satisfaction.

\subsubsection{Physical Absenteeism}

Another issue that arises from professional stress is absenteeism, which occurs when lecturers are seriously ill and believe that they require frequent breaks from a demanding job (Bhui et al. 2012). According to the authors, a secondary issue resulting from teacher absenteeism is that it might lead to a higher rate of pupil dropout. According to Brown and Uehara (2008), "when a quality academic is missing from the classroom, student success suffers". They further claim that research has shown that teacher stress is directly proportional to the total number of days that teachers are absent from school.

\subsubsection{Attrition}

The internal (recognition, sense of achievement, fulfillment) and extrinsic (working environment, management policy) rewards have been the most commonly mentioned predictors of withdrawal (Travers and Cooper, 2012). "Fatigue, routine, irritation and nervous tension" were amongst the reasons given by educators for leaving the profession before retirement, according to Huberman (1993:49) cited by (Skaalvik, 2011). Brown and Uehara (2008), cited by King, Rucker and Duncan (2013), quote research that found that teachers in seven out of ten regions claimed they were considering leaving the profession due to high levels of stress and burnout. These 'possible leavers' showed signs of increased emotional weariness, de-personalization and a lack of personal success in their occupations (Brown and Uehara, 2008).

\section{Methodology}

\subsection{Research Design}

The paper assessed the root causes of female academics' stress in a UoT. Therefore, the qualitative research approach, using a focus group, was employed for the study to gain more in-depth information from the group of female academics.

\subsection{Research Participants}

The target population for this research is $\mathrm{N}=80$, which represents the total number of female academics in the chosen faculty at the UoT in SA. The researchers selected one permanent female academic from each of the departments in the Faculty. Hence, 12 staff members were selected to participate in the focus group.

\subsection{Instrument and Data Collection}

The qualitative interviews took the form of a Focus Group, with unstructured and generally open-ended questions. An Interview protocol was used for asking questions and recording answers during the focus group. As a precaution, the researcher audio recorded the focus group and took manual notes. The interviews with the study participants were tape-recorded, transcribed verbatim and then analyzed using qualitative data analysis.

\subsection{Data Analysis Techniques}

Bell, Bryman and Harley (2019: 198) caution that qualitative research generates large and complex datasets, emanating from the focus group transcripts in this case. Thematic Analysis using NVIVO software was utilized to analyze the data. Themes were generated from the frequencies of the words, phrases and categories used by focus group participants.

\subsection{Ethics Approval and Consent to Participate}

Authors adhered to the Ethics Policy of the University while conducting the research. Permission was granted to collect the data from the targeted participants. 


\section{Results}

\subsection{Workload and Performance Management}

The following results indicate how participants view workload and performance management: "So I can just feed back into that. I think what's happened is our workload has increased over COVID and we don't, we have higher workloads than we did before, which is adding to the stress". "Yes, this is Delta 7. I would like to agree with the other two respondents as well. I think its most definitely the workload has impacted us some way or the other, um I think".

"I just want to touch on some of the points that the colleague have highlighted in some of the elements of performance management. It comes with a lot of not only stress, but job security. But there's always this fear of what are they going to say? Am I doing well? You know, you are always stressed".

\subsection{Teaching vs Research and Administration}

The following results indicate how participants view teaching vs research and administration: "The shift on every five years in terms of your qualification. So if you are not a research-based person to, you are not important. You are just going to be slave driven. But your main purpose is to make sure that your students are taken care of".

"And this pressure to do PhD as I think J-Lo mentioned that because now that people have to go into a PhD. and not many people with PhDs want to do teaching - they want to focus on research".

\subsection{Holidays and Leave}

The following results indicate how participants view holidays and leave:

: "And on top of which we have not had a proper holiday since COVID started because last year, we didn't have a proper holiday this year, that the semester now goes until the $28^{\text {th }}$ of December".

\subsection{Meetings and Support Deficiency}

The following results indicate how participants view meetings and support deficiency:

"So these extended working hours at night, and we still have to be preparing and doing many other things because during the day, there's not enough time for you to do preparations except for attending classes and also for these meetings that are taking place throughout the day. So it has added a lot of stress".

\subsection{Lack of Leave}

The following results indicate how participants view lack of leave:

"I think for me personally one of the major thing is no proper leave or time off for someone to refresh and rejuvenate so we find that we are extremely fatigued and fatigue leads to stress and again affects one's health so I'll just leave it there".

\section{Discussion}

\subsection{Workload and Performance Management, as Well as Family Life and Personal Life}

Work overload, job demands, job control, tight timetables, remuneration imbalances, position ambiguity and conflict are all common stressors that academics face (Leung et al., 2014). The findings of the paper reveal that the root causes of the stressors identified by the participants include workload and performance management. This is in line with Khumalo (2022), who stated that university employees in South Africa work under unreasonable deadlines and heavy workloads. Therefore, leaders need to develop a strategy that can mitigate female academics' stress. Workload compromises personal and family life. Staff members have less time for their families due to meeting work commitments. Sometimes, family members have to be quiet when staff members are in meetings at odd hours, which can impact on relationships. Staff members also have children to attend to. Isa and Palpadan's (2020) finding that instructors' stress levels were also found to be influenced by family issues is relevant to the current sub-theme on work-life balance and family/personal responsibility as a source of occupational stress.

\subsection{Teaching vs Research and Administration}

The paper revealed that the whole concept of 'research' has overshadowed teaching and this has become a stressful area for those academics that are more inclined to 'teaching'. Research-driven pressure: There is considerable research-driven pressure, which can be very stressful for those that are not research-driven. Many academics prefer to just teach, but are now compelled to do research. Research qualifications: The first stressful aspect is to have a minimum of a Master's degree and even PHD qualifications, or face penalties and even retrenchment. The 
administration components also weigh heavily on workload and causes added stress. Academics were seen as administrators because a majority of their work seemed administrative, especially during chaotic registration periods.

\subsection{Covid-19 and Online Teaching and Learning}

A recurring topic that arose during the focus group discussions was the COVID-19 pandemic. Covid-19 has brought added stress in the following ways: Online- Isa and Palpadanan's (2020) study identified sources of stress such as work-related technology to be common amongst Malaysian University lecturers. The Covid-19 pandemic saw a sudden and unexpected transition for lecturers from contact classes to online platforms for teaching. This situation was unprepared for and the participants were overwhelmed by moving to online. The transition to sudden online working has brought about stressors for these female academics. Moreover, there are data and connectivity issue stressors impacting participants in this study. Students often complain to their lecturers that the areas they come from have poor network coverage. In addition, the data limit is inconsistent because some students get more than others, as this is dependent on network provision. The Institution needs to give equal amounts of data because participants are burdened when not all students can attend class or write assessments online.

\subsection{Holidays and Leave and Lack of Leave}

The paper revealed that holidays were now shifted due to the new academic schedule and this affected leave time. Leave was important for one to relax and recharge, and now one takes leave at odd times, if one has the rare opportunity to. The paper revealed that there is no proper leave system in place, especially during the current situation of online teaching. Hence staff cannot take leave easily, which leads to burnout.

\subsection{Meetings and Support Deficiency}

The paper revealed that meetings take place throughout the day and even after hours. This compromises lecture time and preparation. According to the results, participants perceive that there is a severe deficiency of support mechanisms to help staff, which adds to their stress. Furthermore, there is a clear lack of support systems in place to support employees. Staff require teaching and learning support, but management does not provide same. Staff are expected to performance at their optimum but the support is not there. This leads to staff becoming frustrated and stressed. Winefield et al.'s (2008:175) study found that lecturers were not happy with "five aspects of their job (in rank order, university management, hours of work, industrial relations, chance of promotion and rate of pay)". All these stressors relate to a lack of support, which is also perceived as a stressor by the participants in the current study.

\subsection{Resources and Lack of Care and Empathy, as Well as Poor HR}

The paper revealed that staff are not given adequate teaching resources, especially from a technological perspective. Laptops are old and new computers are not provided. This hinders teaching ability. Furthermore, funding resources are not given to obtain additional assistance for teaching and staff become overloaded. Engle's (2012) research revealed that academics report significant levels of stress related to work relationships, control, resources and communication, as well as job uncertainty, excessive overload and work-life balance. This study also found resources and the lack thereof to be a stressor for participants. The paper revealed that the Human Resources Department also does not seem to play a role in taking care of staff. The existence of any HR is to put staff needs first and harness human capital. However, the HR does not do such at the institution and seems more focused on their own promotions.

\subsection{Bullying and Imposition as Well as a Lack of Professionalism, Nepotism and Favouritism}

Poor interpersonal relationships with colleagues or supervisors, workplace harassment or bullying are stressors in this category (Buchanan 2013 in Kruger et al. 2015:96). The findings revealed that bullying and imposition were seen to be evident and a key cause of occupational stress. Workplace bullying was a reality and this was primarily due to HODs not being able to balance mandates from management and staff interests. This means that mandates are imposed on staff and staff are bullied into complying. Relating to the above, the imposition of policy on staff was seen as stressful as staff were not heard and had to comply, irrespective of whether or not it was legal or ethical. The paper revealed that there was also poor workplace professionalism, as indicated by participants' responses. There appears to be nepotism and favouritism amongst staff, which is not addressed.

\subsection{Retrenchments and Stability}

Job insecurity and ambiguity about one's future in the organization are stressful factors (Buchanan, 2013 in Kruger et al. 2015:96). The paper revealed this as a serious issues as it related to the current reality of what staff were going through. Staff without certain qualifications (such as Masters minimum) were being retrenched. This again related to the above, whereby conditions were imposed on staff. Job security therefore became a key stressor. 


\subsection{Recognition and Appreciation}

There is a lack of care exercised by the institution. The concerns of staff are not being heard or addressed. Management seems to do their own thing and impose conditions and mandates. Consequently, staff feel helpless and stress mounts. Relating to the above, there is a lack of empathy. This means that management does not bother to understand what it is that staff are going through. They seem to have an 'if one is not happy, then leave' type of attitude. The myriad occupational stressors identified by the participants in this study has the potential for deleterious consequences for the UoT. Kruger et al. (2015: 99) contend that stress affects everyone differently. Individual effects of stress can manifest physiologically in terms of health impacts like headaches, high blood pressure and heart disease, to name a few; psychologically in the form of strong emotional reactions like anger, anxiety and depression, amongst others; and behaviourally (sleeplessness, drug abuse and disrupted eating habits, for example). Furthermore, Organisational effects of stress can have damaging consequences (Kruger, et al. 2015:101), like increased absenteeism and staff turnover rates, accidents, grievances and labour unrest.

\section{Recommendations}

- Engage with academics on how they deal with stress and advise on the steps that they should take, as well as recognition of the academics as 'experts or professionals';

- University policy-makers should devise a variety of solutions in a well-balanced package that places responsibility on both the university and staff to manage occupational stress;

- To deal with the situation by, for example, having a specific policy on mental health and an active Employee Assistance Programme which staff will definitely utilise; and

- Making stress sensitisation training mandatory for Heads of Department and other line managers who are the first point of contact for lecturers, as well as for all staff in order to empower them to identify mental health issues that may arise for themselves and their colleagues.

\section{Conclusion}

The paper aimed on assessing the root causes of occupational stress amongst female academics in a UoT in SA. The paper revealed that workload and performance management as well as family life and personal life; teaching vs research and administration; Covid-19 and online teaching and learning; holidays and leave and lack of leave; meetings and support deficiency; resources and lack of care and empathy; poor HR, bullying and imposition, as well as a lack of professionalism, nepotism and favouritism, retrenchments and stability, along with poor recognition and appreciation, were the roots that contribute to occupational stress in the UoT in SA. The paper recommends effective interventions to be made for the UoT in order to manage the stress of the female academics, thereby reducing the negative impact thereof on themselves and the institution. Academically, this study has addressed a gap in extant literature on occupational stress amongst female academics in UoTs. No previous studies of this exact nature have been conducted. Therefore, this study is pioneering in the field. In Practice, this study has initiated research on a neglected area in the UoT sector, which may inform institutional practices and policies regarding stress management in Higher Education in South African UoTs. This paper is also a wake-up call, not only to the UoTs but also to all other institutions of higher learning in local, national and international arenas to understand and plan on these roots before it too late.

\section{Acknowledgment}

The authors declare that this is new and original research which has never been submitted to any other journal for publication and there is no financial gain. There is no such competing interest.

\section{References}

Bhui, K. S., Dinos, S., Stansfeld, S. A., \& White, P. D. (2012). A synthesis of the evidence for managing stress at work: a review of the reviews reporting on anxiety, depression, and absenteeism. Journal of Environmental and Public Health, Article ID 515874, 1-21. https://doi.org/10.1155/2012/515874

Bickford, M. (2005). Stress in the workplace: a general overview of the causes, the effects, and the solutions. Canadian Mental Health Association Newfoundland and Labrador Division, 8(1), 1-3.

Breakwell, G. M. (2015). Coping with threatened identities. London: Routledge. https://doi.org/10.4324/9781315733913

Brown, Z. A., \& Uehara, D. L. (2008). Coping with teacher stress: A research synthesis for Pacific education. Research Series. 
Bryman, A., \& Bell, E. (2011). Ethical Considerations. Research Methodology, 122-128.

Bryman, A., \& Bell, E. (2019). Research methods for business students. $5^{\text {th }}$ ed. Oxford: Oxford University Press.

Bryman, A., Bell, E., Mills, A. J., \& Yue, A. R. (2007). Business research strategies. In: Business research methods, $2^{\text {nd }}$ ed. Oxford: Oxford University Press, 226-238.

Buchanan, D. A., \& Huczynski, A. A. (2019). Organizational behaviour. Pearson UK.

Champoux, J. E. (2010). Organizational Behaviour: Integrating individuals, groups, and organizations. London: Routledge. https://doi.org/10.4324/9780203872918

Collie, R. J., \& Shapka, J. D. (2012). School climate and social-emotional learning: Predicting teacher stress, job satisfaction, and teaching efficacy. Journal of Educational Psychology, 104(4), 1189-1204. https://doi.org/10.1037/a0029356

Dandona, A. (2014). A study on occupational stress of lecturers and physicians. International Journal of Law, Psychology and Human Life, 3(1), 1-6.

Davis, E. M., Stange, K. C., \& Horwitz, R. I. (2012). Childbearing, stress and obesity disparities in women: a public health perspective. Maternal and Child Health Journal, 16(1), 109-118. https://doi.org/10.1007/s10995-010-0712-6

Devonport, Tracey \& Lane, Andrew. (2008). Relationships between self-efficacy, coping and student retention. Social Behavior and Personality an International Journal, 34. https://doi.org/10.2224/sbp.2006.34.2.127

Dhar, N., \& Magotra, R. A. (2018). Study of the occupational stress among teachers teaching in JKBOSE \& CBSE in Jammu District: A comparative study. International Journal of Advanced Research in Education \& Technology, 5(1), 23-27.

Gold, Y., \& Roth, R. A. (2013). Teachers managing stress \& preventing burnout. London: Routledge. https://doi.org/10.4324/9780203209899

Greenglass, E. R. (2005). Proactive coping, resources and burnout: implications for occupational stress. Research Companion to Organizational Health Psychology, 503-515. https://doi.org/10.4337/9781845423308.00043

Harmsen, R., Helms-Lorenz, M., Maulana, R., \& van Veen, K. (2018). The relationship between beginning teachers' stress causes, stress responses, teaching behaviour and attrition. Teachers and Teaching, 24(6), 626-643. https://doi.org/10.1080/13540602.2018.1465404

Hitt, M. A., Miller, C. C., Colella, A., \& Triana, M. (2018). Organizational behaviour. John Wiley \& Sons.

Hudson-Allez, G. (1999). The treadmill syndrome. The Psychologist, 12, 548-549. Available: psy_11_99_p548-549_hudson.pdf (thepsychologist.s3.eu-west-2.amazonaws.com)Accessed 10 January 2020).

Khumalo, N. (2022). Factors That Affect the Morale of Employees in the Institution of Higher Learning in South Africa. International Journal of Higher Education, 11(3), 58-66. https://doi.org/10.5430/ijhe.v11n3p58

King, D., Rucker, K. J., Duncan, D. W., \& Boland, K. J. (2013). A comparison of job stressers experienced by male and female beginning agriculture teachers. University of Georgia. CAES General Publications.

Kinman, G. (2016). Managing the work-home interface: The experience of women academics. In: Exploring resources, life-balance and well-being of women who work in a global context, 127-144. https://doi.org/10.1007/978-3-319-31736-6_8

Lazarus, R., \& Folkman, S. (1984). Stress, Appraisal, and Coping. New York: Springer.

Leung, M. Y., Liang, Q., \& Olomolaiye, P. (2014). Impact of job stressors and stress on the safety behavior and accidents of construction workers. Journal of Management in Engineering, 32(1), 04015019. https://doi.org/10.1061/(ASCE)ME.1943-5479.0000373

Nambei, S., \& Mefi, N. (2020). Stress related challenges faced by primary school teachers in rural municipality in Eastern Cape. Academy of Entrepreneurship Journal, 26(4), 1-21.

Prabu, P. S. (2015). A study on academic stress among higher secondary students. International Journal of Humanities and Social Science Invention, 4(10), 63-68.

Raza, H. (2012). Getting higher education: Is it really a challenge for females in Pakistan? Academic Research International, 2(3), 352-360. 
Schwarzer, Ralf \& Renner, Britta. (2009). Health-Specific Self-Efficacy Scales.

Singh, J., Steele, K., \& Singh. L. (2021). Combining the Best of Online and Face-to-Face Learning: Hybrid and Blended Learning Approach for COVID-19, Post Vaccine, \& Post-Pandemic World. Journal of Educational Technology Systems, 50(2), 140-171. https://doi.org/10.1177/00472395211047865

Skaalvik, E. M., \& Skaalvik, S. (2015). Job satisfaction, stress and coping strategies in the teaching profession-what do teachers say? International Education Studies, 8(3), 181-192. https://doi.org/10.5539/ies.v8n3p181

Tight, M. (2012). Researching higher education. McGraw-Hill Education (UK).

Travers, C. (2017). Current knowledge on the nature, prevalence, sources and potential impact of teacher stress. Educator Stress, 23-54. https://doi.org/10.1007/978-3-319-53053-6_2

Wadesango, N., Gudyanga, E., \& Mberewere, M. (2015). Occupational stress among school head teachers: A case for Hwedza District secondary schools' head teachers. Journal of Social Sciences, 45, 31-35. https://doi.org/10.1080/09718923.2015.11893484

World Health Organisation. (WHO). 2017. Work organisation and stress. Available: https://www.who.int/occupational_health/publications/en/oehstress.pdf (Accessed 11 February 2021).

\section{Copyrights}

Copyright for this article is retained by the author(s), with first publication rights granted to the journal.

This is an open-access article distributed under the terms and conditions of the Creative Commons Attribution license (http://creativecommons.org/licenses/by/4.0/). 